\title{
Improving care home design for people with dementia
}

\author{
Fiona Kelly, Anthea Innes and Ozlem Dincarslan \\ University of Stirling, UK
}

\begin{abstract}
With more people with dementia living in care homes in the UK than ever before, there is growing recognition that the design of such internal and external spaces should meet dementia friendly principles. This paper reports on one part of a study to evaluate the reliability and validity of two tools: The Design Audit Tool and the Environmental Audit Tool developed to audit how dementia-friendly internal and external environments (specifically care homes) are for people with dementia, and presents a qualitative analysis of the reports presented to care homes following each audit. Thirty care homes took part in the study to evaluate the design audit tools and, following good practice, received a home report detailing up to five design strengths and five limitations following the audit. Analysis of the home reports identifies variation and variability in meeting dementia-friendly principles as specified by both tools. Areas of variability included wayfinding, the use of colour and contrast, access to outside spaces, individualization of personal and communal spaces, lighting and opportunities to engage with the environment. This paper provides valuable insights into variability in care home design and identifies common areas of weakness and strength in care homes of different type, ownership and localities.
\end{abstract}

Keywords: Care home, dementia, design audit tool, environment, design

\section{Principal Management Implications}

- There are increasing numbers of people with dementia living in care homes.

- International design principles guide 'dementia-friendly' design.

- Dementia-friendly design (in internal and outdoor spaces) is increasingly recognized as an important research and practice area

required as part of the process of achieving quality care for people with dementia.

- Design should be enabling rather than disabling and should maximize the person's ability to engage with the environment.

- Those planning new buildings or refurbishing existing buildings likely to be inhabited by people with dementia need to ensure they are dementia-friendly.

- Those providing and commissioning care for people with dementia need also to seek ways to support and maximize independence and well-being of those who live there through enabling design.

- Outside space is a crucial area that care homes can build on to enhance care-providing environments.

- Wayfinding aids present a key opportunity to maximize the experience of living in a care home.

- There are simple measures care home managers, owners and staff can take to improve the physical environment of care.

\section{Introduction}

There are an estimated one-third of people with dementia living in care homes in the United Kingdom with up to $70 \%$ of the care home population possibly having some form of dementia. ${ }^{3-4}$ While there has been little planning for this increasing population in care homes, ${ }^{4}$ there is increasing recognition of the importance of good design for the well-being of people with dementia, and particularly that the design of buildings can be enabling or disabling for those who work and/or live there. ${ }^{5}$ Research has shown that, in institutional settings, residents often experience the environment as restrictive and confining. ${ }^{6}$ For example, Parker et al.' $\mathrm{s}^{7}$ study indicates relationships between the built environments of care homes and the quality of life of those who live and work there, in particular 
a negative association between stringent health and safety requirements and quality of life. Similarly, Torrington ${ }^{8}$ found a negative relationship between quality of life and buildings that prioritized safety and health, and positive effects of a range of attributes, including community contact, physical support, comfort and control and personalization. There is also growing recognition that while a person with dementia can be at risk because of impairment, they must still be able to live their lives and do as much as they can. ${ }^{5}$ The environment needs to be able to support remaining ability rather than operate to diminish $\mathrm{it}^{5}$ and to support the development and maintenance of relationships. ${ }^{6}$ Thus, design of buildings, if regarded as a therapeutic resource, can promote well-being and functioning of people with dementia. ${ }^{9}$ Chalfont and Rodiek $^{10}$ argue that we need to move away from designing buildings or indoor and outdoor spaces for the purposes of control or surveillance or to diminish behavioural difficulties towards considering how environments can encourage curiosity and engagement in everyday activities. This is as important for the outside as inside environments. ${ }^{11}$ Utton $^{12}$ also suggests that design should accommodate current demands while remaining flexible to future changes in attitude and living style.

This suggests that buildings and spaces should be 'dementia-friendly' if they are to contribute to enhancing the quality of life of those who live and work there. A dementia-friendly environment should compensate for disability and should consider the importance for the person with dementia of his/her experiences within the environment. Davis et al. ${ }^{5}$ define dementia-friendly environments as:

a cohesive system of support that recognizes the experiences of the person with dementia and best provides assistance for the person to remain engaged in everyday life in a meaningful way.

This definition highlights a shift in emphasis from care environments designed to keep people safe and meet their physical needs to care environments that are designed to maximize existing skills and retain independence. International consensus principles $^{13}$ on design for dementia propose that design should:

- compensate for disability;

- maximize independence;

- enhance self-esteem and confidence;

- demonstrate care for staff;
- be orientating and understandable;

- reinforce personal identity;

- welcome relatives and the local community;

- allow for stimuli.

This international consensus also suggests that specific design features include:

- small size;

- familiar, domestic, homely in style;

- plenty of scope for ordinary activities;

- unobtrusive concern for safety;

- different rooms for different functions;

- age-appropriate furniture and fittings;

- safe outside space;

- single rooms big enough for lots of personal belongings;

- good signage and multiple cues where possible;

- use of objects rather than colour for orientation;

- enhancement of visual access;

- controlled stimuli, especially noise.

Adhering to dementia-friendly design principles allows staff and management to gain an understanding of any problems that are caused by the environment where people with dementia live and allow for the implementation of short and longterm plans for its improvement. ${ }^{2}$ It is also recognized that people with dementia respond on a sensory level to their environment - therefore the indoor environment should be designed so that what people with dementia see, hear, feel, smell and touch all give them the same consistent information about the environment in order for them to understand it fully. ${ }^{14}$ van Hoof et al. ${ }^{15}$ provide an excellent overview of indoor environmental parameters in relation to the intrinsic ageing of the senses, which can help designers to create optimal environmental conditions for people with dementia.

This paper reports on the findings reported to care homes who participated in a study evaluating two audit tools $^{1,2}$ about the strengths and limitations of the physical environment based on the dementiafriendly principles common to both tools. Fieldwork was conducted between April 2009 and March 2010 in 30 care facilities in Central Scotland and Northern Ireland. Findings from the main study are reported elsewhere. ${ }^{16}$

The design audit tool (DAT) was designed by the Dementia Services Development Centre (DSDC), University of Stirling to help structure consultancies commissioned by care homes to examine the environments where dementia care is delivered. The tool was developed by an inter-disciplinary team, including occupational therapists, lighting 
and design consultants, practitioners and architects and was field-tested through pairings of practitioners and architects to ascertain its usability for consultancy purposes. It is a detailed and lengthy paper-based document comprising 11 different sections named 'units'. Each unit is subdivided into a number of criteria/questions for the auditor to score on a three-point scale - met, part met and not met. In total there are 181 questions. However, as the tool instructs the user to include a proportion (around 20\%) of bathrooms, toilets and bedrooms, the number of questions per audit to be included will vary. In addition, homes organized into smaller units often have multiple lounges and dining rooms, which again impacts on the total number of questions included per audit. In our research this ranged from 155 to 494 questions. The average number of questions across the 30 care homes in our sample was 280.

The environmental audit tool (EAT) was developed for the New South Wales Department of Health by Fleming et al. $(2003)^{2}$ in response to a growing realization of the importance of good design for good practice and the well-being of those who live there. It is a much shorter paperbased document, comprising 72 questions grouped into ten conceptual domains; for example, safety and security, familiarity and links to community. Unlike the DAT, there are no requirements to audit a percentage number of rooms.

\section{Aims}

This paper aims

- to identify key design principles that constitute dementia-friendly design;

- to highlight areas where care homes do or do not meet internationally agreed design principles for people with dementia;

- to offer ways in which design of care homes can be improved.

\section{Design}

Ethical approval was granted by the University of Stirling departmental ethics committee prior to the set up or conduct of fieldwork. Local ethics processes were followed in accordance with the requirements of the different organizations who granted us access to their care homes and consent processes adhered to University of Stirling protocol.

Care homes were selected from a database compiled by the research team based on their claims that they provided dementia care. Care homes willing to participate in the study were drawn
Table 1: Care home characteristics.

\begin{tabular}{llll}
\hline Building type & Voluntary & Statutory & Private \\
\hline Purpose built & 4 & 4 & 15 \\
Converted & 5 & 0 & 2 \\
\hline
\end{tabular}

from private, voluntary and statutory sectors and included purpose built and converted buildings. Thirty care homes were audited by two researchers using both audit tools; 24 of these were in Scotland and six in Northern Ireland. They ranged from 11 to 96 beds, with the average number of beds being 47 . See Table 1 for care home characteristics.

Each audit involved walking around the care home and documenting, according to the rules of each tool, the presence or absence of specific design features. As part of good practice, the researchers sent each care home a short report detailing no more than five design positives and five design limitations noted during the audit, based on the design principles of both tools.

\section{Analysis and Findings of Home Reports}

The home reports were developed using initial qualitative interpretations and analysis of the audit process in each home, derived from detailed paired debriefing notes following each audit, and from the actual data collected through each audit tool. One researcher decided the format of all home reports should take to ensure that all homes received feedback in a consistent manner and one researcher from each audit drafted the initial home report. The content of each home report was then verified by a second researcher to ensure that a rigorous analytical process was adopted in this part of the process. The 30 home reports were then subjected to a further thematic analysis to identify any commonalities and differences across them; this analysis is the focus of this paper. Six key themes were identified and will be discussed in turn:

1. wayfinding;

2. use of colour;

3. individualization of space;

4. outside space;

5. lighting;

6. opportunities for engagement with the environment.

\section{Wayfinding}

Wayfinding refers to the ease with which people can get from $A$ to $B$ and can be supported through visual cues, such as understandable, easily visible signage, 
the use of visual cues, for example a picture of a plate of food to signify the dining room or through landmarks to orientate people as to where in the building they are. Twenty-five (83\%) homes audited were identified as having limitations in wayfinding, signage or visual cues. The following is a typical limitation noted in care home reports:

Although there are some signs on the doors, these are not always consistent and the home lacks directional signage in strategic places so that the residents can find their way to communal areas, toilets and corridors easily. (care home 20)

In six $(20 \%)$ of the homes, this was reported as a limitation more than once, reflecting a problem with wayfinding in these settings. Thus, although some areas of a care home could have good signage promoting wayfinding, this was not generally a universally applied technique. Wayfinding is an important issue for anyone wanting to navigate a space and this is particularly the case in relation to toilets. A setting could receive a positive comment about wayfinding in general, but require prompting to ensure wayfinding was consistently applied in accordance with dementia-friendly principles of the audit tools. Wayfinding to toilets was a notable area requiring improvement:

Although there are some signs on some toilet doors, there seems to be a lack of signage indicating which way to go. (care home 1)

The majority of care homes had limitations in this area and this was one particular issue that people with dementia commented on when researchers asked them for their views. ${ }^{16}$ Given the concern to promote continence ${ }^{17}$ this is an area that care homes could address with relative ease and at a relatively low cost.

\section{Use of Colour}

Alzheimer's disease has been shown to affect visual function in a variety of ways, including visuospatial processing and visuomotor coordination. ${ }^{18}$ Further, ageing eyes gradually lose the ability to distinguish between similar colour tones, for example between blues and greens or pinks and reds. Experts have suggested that colour can be used to great effect in care home environments, not only to enhance mood, but also to aid in wayfinding and to enhance visibility of useful or important features. ${ }^{19,20}$ Therefore making use of strongly contrasting colours which draw attention to areas that are used by residents, such as doors to bedrooms contrasting with door frames, or to aid residents' independence with important activities of daily living, such as toilets contrasting with toilet seats, is recommended. ${ }^{1}$

Use of colour, or the limited use of it, was commented on in all 30 home reports in some way. The main area where limitations were reported was the poor use of contrast in bathrooms, shower rooms and toilet areas. In ten homes (33\%) audited, poor contrast/colour usage was raised in more than one of the feedback points. For example:

Use is not made of colour contrasts throughout the home. For example handrails do not contrast with the surrounding walls and toilet seats do not contrast with the toilet bowl. (care home 2)

and

Many of the doors do not contrast well enough with the surrounding walls, handles on doors do not contrast well with the doors, handrails in toilets and bathroom areas are often white against white or very pale background. (care home 13)

However, 16 homes (53\%) received positive feedback on a particular aspect of colour and contrast usage; one home in particular received three feedback points that referred to good use being made of colour and colour contrast, with a further three $(10 \%)$ receiving positive feedback on two examples of good use of contrast. For example:

There is fantastic use of contrast in the unit. For example, the handrails in the corridors and bathrooms contrast with the background wall, toilet seats contrast with floor and toilet bowl, brilliant use of consistent and contrasting colour for toilet doors and wonderful use of colour to individualize bedroom doors. (care home 10)

Analysis of home reports suggests the use of colour and contrast for these purposes in care homes varied considerably; therefore more focus on the different functions of colour and contrast in the design or refurbishment of buildings for people with dementia is recommended.

\section{Individualization of Personal and Communal Spaces}

Following international consensus ${ }^{13}$ on designing care homes for people with dementia, the 'homeliness' of the setting is important, that is the extent 
to which it feels more like home and less like an institutional setting. The importance of having familiar and treasured items relates not only to a sense of security and association with a place, but also helps to create an individualized, personal or homely feel.

Eighteen $(60 \%)$ care homes received feedback alerting them to the lack of personalization in the home. For example, some care homes had a uniform approach to residents' bedrooms with identical bedding, layouts, furniture and colour schemes making it very difficult for one resident to distinguish between their own bedroom and that of other people living in the building. For example:

Personalisation of rooms could be enhanced, for example through the introduction of individual duvet covers (rather than the same style and pattern throughout the building). This would be a simple way to make each room more individualized and therefore easily recognizable to each resident. (care home 12)

Opportunities for helping residents to find their own bedrooms through personal items, signage and colour were fed back to care homes where little attempt had been made to help residents orientate themselves and their personal space in the large building, for example:

The bedroom doors would benefit from personalization for each resident which can be achieved by adding items like memory boxes to each door, picture of the resident (or something that is meaningful to them) in addition to their name and room number so that there is a feeling of individuality for each room. In addition, the colours of the bedroom doors could be changed to different colours for each resident. (care home 20)

Eighteen $(60 \%)$ homes received varying degrees of positive feedback on particular ways they had tried to encourage individualization of space. These homes had made attempts to personalize bedrooms, and corridors where bedrooms were located.

The bedrooms we have seen were lovely bright rooms with good views of the garden. Residents had their personal belongings, some own furniture, pictures, cuddly toys which personalized the rooms very well. (care home 19)
This corresponds with findings from Innes et al. ${ }^{16}$ of the importance for people with dementia and their families of having familiar or treasured possessions in residents' personal spaces. There was, however, variety in the individualization or personalization of communal spaces, that is, the extent to which they also felt homely:

There seemed to be a lack of stimulation within the general environment, although there is ample space for it. In the lounge area, the only stimulation is the television and there is lots of space within the unit to accommodate other items such as table football or similar activity items. The unit as a whole could benefit from being made more homely and accommodating, such as having bookshelves, ornaments and seating at strategic places in hallways (wherever this is possible). (care home 21)

In contrast to this home report:

This is a lovely, homely, spacious and comfortable home with plenty of character. There are several lounge areas and lots of nooks with seating to address different wishes, such as a smoking lounge, TV areas, family room in the conservatory, an extra smoking lounge in the basement which is used mostly by one resident as well as the reminiscence room. The small hallway between the two houses is used to display the beautiful artwork the residents and family carers create which is excellent use of this space. (care home 30)

Torrington ${ }^{21}$ argues that successful spaces are those that carry unambiguous meaning. Often in care homes, the size of the space can conflict with the size of a space normally encountered at home (sitting room or dining room). Further, the furniture and fittings chosen for their 'homeliness' may look inappropriate and incongruous in a large space and may increase confusion rather than making people 'feel at home'. Thus, consideration should be given to how the size of a space impacts on the meaning of that space for people with dementia, and this is particularly the case with communal spaces such as dining or sitting rooms.

\section{Outside Space}

Going outside, or at least a sense of being able to go outside, is crucial for good physical and mental health. ${ }^{22}$ Chalfont ${ }^{11}$ stresses the need for design to allow for access to the outside world. This can range from windows which allow entry of sufficient 
natural light: to maintain diurnal rhythm (waking and sleeping patterns); reduce possibility of seasonal affective disorder; allow views to outside spaces or facilitate sensory stimulation (sight, smell, sound, feel of wind on skin and sun on face). Outside spaces can include ground-level gardens, or for care homes on different levels, balconies, roof terraces or roof gardens ${ }^{13}$; these are relatively rare in the UK, although are increasing in number as the importance for well-being of access to an outside space (however small) increases. Outside spaces can provide a different view on the world and offer places of quiet that can be hard to find inside. ${ }^{23}$ Duggan et al. ${ }^{24}$ explored the experiences of people with dementia who lived at home of going outside and report strong consensus on the desirability and pleasure of going outside, and the negative effects of not going out regularly. While derived from interviews with people with early to moderate dementia living at home, these findings are likely to resonate with people with dementia living in care homes.

Twenty-eight (93\%) of the homes received positive comments about the outside space reflecting the presence of gardens, courtyards and grounds that were part of the design of the homes, for example:

The garden is lovely and well designed with a circular pathway. There are many features that encourage meaningful activity such as the raised herb bed, sheltered seating areas, a garden shed, bird table and sensory planting. (care home 8).

However, 18 (60\%) also received some negative feedback on the outside space and these often related to under-utilization of the space, insufficient or inadequate seating or safety issues such as uneven paving or insecure fencing:

Whilst the existence of a garden area is excellent in this building, it seems to be under-utilized. The addition of the pergola is a lovely idea, however, the seating in there is limited. (care home 25)

Those who lived in care homes with multiple levels, most often those with dementia, had limited or no independent access to outside spaces and this was reported on in four (13\%) home reports, for example:

The garden area is lovely, however it only seems to be easily accessible from the downstairs unit. (care home 16)
This is an important point; the presence of a lovely outside space does not necessarily equate to easy or any access to it by people with dementia who live there. This is despite the literature on the value of access to outdoor spaces for people, including those with dementia. ${ }^{11}$

\section{Lighting}

Visual processing is influenced by optical factors: the amount of light reaching the retina through the pupil and lens and by neural factors such as rod and cone cell density and ganglions in the retina and optic nerves. These elements all change with age and, to varying degrees, impact negatively on visual processing ${ }^{25}$ and therefore on the ability to engage with the environment. ${ }^{26}$ Recommendations for ensuring dementia-friendly lighting include increasing light levels to twice normal levels, using domestic style fittings to help promote recognition of place, using daylight wherever possible and exposing people to the 24-hour cycle of light and dark. $^{26}$

Fifteen $(50 \%)$ of the homes received positive feedback relating to good natural light in particular areas of the building:

Throughout this unit, good use has been made of glass panels and natural lighting. For example the glass panels provide visual access for the dining room and lounge. The ceiling glass cupola in the wings with bedrooms and also in the area beside the doors to the garden, are excellent design features and provide natural light to corridor areas. (care home 15)

However, even when there were large or multiple aspect windows in sitting rooms or other communal spaces, these were sometimes blocked by furniture (commonly armchairs), obscuring the view and reducing the amount of light entering the room:

The low level window sills allow natural light into the lounge area and views onto the garden. Consideration of where to place chairs in this room to maximize opportunities to go out of the French doors into the garden and to place chairs to maximize views would enhance the use of this space. (care home 7)

It was noted for 10 homes (33\%) that there was a lack of natural light, poor use of artificial light promoting glare or insufficient wattage light bulbs to help brighten up very dark areas in the building, for example: 
Both the overhead and the wall mounted lights produced insufficient light in the corridors leading to the bedrooms. (care home 11)

In these care homes, there seemed to be insufficient understanding of the need for adequate lighting to compensate for age-related deterioration in visual processing and is an area that can be relatively easily rectified by using appropriate wattage bulbs. ${ }^{26}$

\section{Opportunities for Engaging with the Environment}

Torrington' $\mathrm{s}^{8,21}$ research aimed to gain an understanding of what the various spaces of a care home meant for those who lived there. Torrington ${ }^{21}$ reports a 'wish list' of favourite activities derived from conversations with people with dementia living in care homes, at home or in residential care, including access and connection to the natural world, community participation, participation in creative activities and support with routines. Torrington ${ }^{21}$ points to the importance for well-being of a physical environment that is designed to support activity of different types and provides opportunities for such activities to occur. Orrell et al. ${ }^{27}$ report levels of unmet social and psychological needs as reported by people with dementia living in care homes, highlighting the continued gap in provision for these aspects of care.

Analysis of home reports indicates opportunities for residents to engage with their environment ranged from domestic, small scale, well-decorated and accessorized spaces, to provision of activities in certain rooms (hairdressing salon, activities room, kitchen area used by residents). Four (13\%) care homes received more than three feedback points highlighting good use of space to help residents engage with the place they lived in and a further nine $(30 \%)$ received two points of feedback highlighting good availability or good use of space, for example:

There are lots of interesting items and pictures on the walls, in display cabinets and within the nooks at entrances to the hallways which also had some seating. The choice of items (e.g. old typewriter and wooden phone, dresser with relevant grooming items, pram etc.) with some corresponding images on the walls made these little areas very interesting to be in. Inclusion of items that are familiar to residents can aid reminiscence and wayfinding and provide a way to engage with the environment and with others in conversation. (care home 13)
However, 17 homes (56\%) received comments highlighting a lack of stimulation, opportunities for activity, lack of creativity and little attempt to make either an individual room or space attractive to residents. This ranged from dark, long corridors leading to locked fire doors, to sterile and clinical rooms for bathing. For example:

There were many locked doors throughout the building, restricting opportunities for walking, exploring and generally engaging with the environment. The internal long corridor between the two dementia units leads to three locked doors. The locked doors to the garden from this corridor that adjoins the large space prevent ease of access to the outdoor walkway. (care home 15)

This is a very important issue for people living in care homes as the availability of different rooms for different purposes, the availability of activities and the availability of quiet spaces all impact on the quality of living experience. As Davis et al. ${ }^{5}$ argue, shifting thinking from 'condition' to 'experience' has the potential to facilitate the shift in culture needed to create environments that allow the person with dementia to be an active participant in everyday life rather than a recipient of care.

\section{Discussion}

This paper has reported on the analysis of 30 care home reports developed and sent to care homes that participated in a study to evaluate the reliability and validity of two DATs. ${ }^{1,2}$ Analysis of these reports offer a valuable insight into the variation in care home design and show that, despite international design principles ${ }^{13}$ and emerging policy, ${ }^{4}$ there are areas in which care home design is not serving the interests of people with dementia who live there. These include supporting wayfinding, using colour and contrast to compensate for difficulties with visual processing, ensuring personalization of space, particularly private spaces, ensuring the environment is as homely as possible and providing access to pleasant outside spaces.

People with dementia are users of the physical environment; they navigate and walk through it, engage with it and attempt to make sense of it. This paper has illustrated how their ability to navigate or meaningfully use space depends on whether the design of internal and external spaces enables or restricts its use. Thus, just as the quality of care can impact of the experiences of people with dementia, 
so can the quality of environmental design. ${ }^{28}$ Indeed, Nolan et al. ${ }^{29}$ demonstrate that placing items (photographs and significant memorabilia) in memory boxes outside the door of each person's bedroom, increases (by $45 \%$ ) the ability of people with dementia to find their way to their bedrooms. Their study is significant as it illustrates a relatively simple way of maximizing the usability of the building for people with dementia who live there, and thereby increasing or maintaining their independence. Findings from Innes et al.'s ${ }^{16}$ study, where focus groups were held with people with dementia and their family members to identify what was important to them in terms of the design of the building they lived in, reinforces the fact that people with dementia want to be independent, and this means also being able to choose where and how to spend their time. In order to achieve independence and well-being, Blackman et al. ${ }^{28}$ argue for:

Shifting the focus from the disorientated, confused and distressed person, and the private sphere of personal medical tragedy, to the issue of disorientating, confusing and distressing environments, and the public sphere of planning and design.

This puts a responsibility on those planning new buildings or refurbishing existing buildings that are or are likely to be inhabited by people with dementia to ensure they follow dementia-friendly principles. Those providing and commissioning care for people with dementia also need to seek ways to support and maximize independence and well-being of those who live there by considering design that enables rather than disables and by reviewing the setting to ensure it continues to meet design-friendly principles. As evidenced by the findings from this small study, there is still some way to go.

\section{Conclusion}

This paper has reported on a qualitative analysis of reports sent to 30 care homes following their participation in a study to evaluate the reliability and validity of two tools designed to audit how dementiafriendly care home design is for people with dementia who live there. Thematic across-case analysis of these reports has provided a valuable insight into the variation and variability of the quality of care home design as specified by international design principles and has identified where care homes need to focus on to become better places for people who live and work there.

\section{Acknowledgements}

With thanks to the people with dementia, managers and staff who allowed us into their care homes. The research was funded by the Dementia Services Development Trust (DSDT).

\section{References}

1. Cunningham C, Marshall M, McManus M, Pollock R, Tullis A. Design for people with dementia: audit tool. University of Stirling, Dementia Services Development Centre, Stirling; 2008.

2. Fleming R, Forbes I, Bennett K. Adapting the ward for people with dementia. New South Wales: Department of Health; 2003.

3. Scottish Government. Scotland's national dementia strategy. Edinburgh: The Scottish Government; 2010.

4. Department of Health. Living well with dementia: A national dementia strategy. London: HMSO; 2009.

5. Davis S, Byers S, Nay R, Koch S. Guiding design of dementia friendly environments in residential care settings: considering the living experiences. Dementia 2009; 8(2): 185-203.

6. Wiersma E, Pedlar A. The nature of relationships in alternative dementia care environments. Can J Aging 2008; 27(1): 101-8.

7. Parker C, Barnes S, McKee K, Morgan K, Torrington J, Tregenza P. Quality of life and building design in residential and nursing homes for older people. Ageing Soc 2004; 24: 941-62.

8. Torrington J. Evaluating quality of life in residential care buildings. Building Res Inf 2007; 35(5): 514-28.

9. Day K, Carreon D, Stump C. The therapeutic design of environments for people with dementia: A review of the empirical research. Gerontologist 2000; 40(4): 397-416.

10. Chalfont G, Rodiek S. Building edge: an ecological approach to research and design of environments for people with dementia. Alzheimer's Care Q, Special Issue - Environ Innovations Care 2005; 6(4): 341-8.

11. Chalfont G. Design for nature in dementia care. London: Jessica Kingsley Publishers; 2008.

12. Utton D. The design of housing for people with dementia. J Care Serv Manag 2009; 3(4): 380-90.

13. Marshall M. Therapeutic buildings for people with dementia. In: Judd S, Marshall M, Phippen P (eds.) Design for dementia. London: Journal of Dementia Care; 1998.

14. Zeisel J. Environment, neuroscience and Alzheimer's disease. Alzheimer's Care Q 2005; 6(4): 273-9.

15. van Hoof J, Kort H, Duijnstee M, Rutten P, Hensen J. The indoor environment and the integrated design of homes for older people with dementia. Building Environ 2010; 45: 1244-61.

16. Innes A, Kelly F, Dincarslan O. Care home design for people with dementia: what do people with dementia and their families value? Aging Mental Health 2011; forthcoming.

17. Hagglund D. A systematic literature review of incontinence care for persons with dementia: the research evidence. Journal of Clinical Nursing 2010; 19: 303-12.

18. Rizzo M, Anderson S, Dawson J, Nawrot M. Vision and cognition in Alzheimer's disease. Neuropsychologia 2000; 38: 1157-69. 
19. Brawley E. Designing for Alzheimer's disease: strategies for creating better care environments. New York: John Wiley \& Sons; 1997.

20. Arditi A. Enhancing the visual environment for older and visually impaired persons. Alzheimer's Care Q 2005; 6(4): 294-9.

21. Torrington J. What has architecture got to do with dementia care: explorations of the relationship between quality of life and building design in two EQUAL projects. Qual Ageing - Policy, Pract Res 2006; 7(1): 34-48.

22. Marshall M. Designing balconies, roof terraces and roof gardens for people with dementia. University of Stirling. Dementia Services Development Centre, Stirling; 2010.

23. Brawley E. Environmental design for Alzheimer's disease: a quality of life issue. Aging Mental Health 2001; 5(S1): 79-83.

24. Duggan S, Blackman T, Martyr A, Van SP. The impact of early dementia on outdoor life: A 'shrinking world'? Dementia 2008; 7(2): 191-204.

\section{Author Information}

Fiona Kelly is a Lecturer in Dementia Studies at the Dementia Services Development Centre (DSDC), School of Applied Social Science, University of Stirling. She is also a practicing nurse. Teaching and research interests include palliative and end of life care, improving practice in long-term care and dementia-friendly design.

Ozlem Dincarslan is a Research Assistant at the Dementia Services Development Centre (DSDC), School of Applied Social Science, University of Stirling. Her interests include supporting those who work in the home care sector, service improvement for people with dementia and their carers and dementia-friendly design.
25. Boyce P. Lighting for the elderly. Technol Disabil 2003; 15: 165-180.

26. McNair D, Cunningham C, Pollock R, McGuire B. Light and lighting design for people with dementia. University of Stirling. Dementia Services Development Centre, Stirling; 2010.

27. Orrell M, Hancock G, Galboda LK, Woods B, Challis D, Hoe J. The needs of people with dementia in care homes: the perspectives of users, staff and family caregivers. Int Psychogeriatrics 2008; 20: 941-51.

28. Blackman T, Mitchell L, Burton E, Jenks M, Parsons M, Raman S, et al. The accessibility of public spaces for people with dementia: a new priority for the 'open city'. Disabil Disabil Soc 2003; 12(3): 357-71.

29. Nolan B, Mathews M, Truesdell-Todd G, VanDorp A. Evaluation of the effect of orientation cues on wayfinding in persons with dementia. Alzheimer's Care Q 2002; 3(1): 46-9.

Anthea Innes is a Senior Lecturer in Dementia Studies at the DSDC, School of Applied Social Science, University of Stirling. She has specialized in dementia care research and education for over a decade. Her research focuses on frontline care work, the experiences of people with dementia and their family caregivers, rural dementia care and early diagnosis and post-diagnostic support for people with dementia. 